\title{
Electronic System for Controlled Modification of Temperature Field in Sheet Metal Blanks
}

\author{
Radek Holota ${ }^{1}$, Václav Koucký², Petr Krist ${ }^{3}$, \\ Pavel Valenta ${ }^{4}$ \\ Dept. Applied Electronics and Telecommunications \\ University of West Bohemia \\ Plzeň, Czech Republic \\ 'holota5@kae.zcu.cz, ${ }^{2}$ koucky@kae.zcu.cz, \\ ${ }^{3}$ krist@kae.zcu.cz, ${ }^{4}$ valpav@kae.zcu.cz
}

\author{
Bohuslav Mašek ${ }^{5}$ \\ Kovovýroba HOFFMANN, s.r.o. \\ Ostrožská Nová Ves, Czech Republic \\ ${ }^{5}$ masekb@rice.zcu.cz
}

\begin{abstract}
Technology for modifying the local temperature of a material is tested for hot forming. A system for selective controlled cooling was designed for this purpose and a workplace enabling heating, local cooling and material forming was built. This paper describes the principles and possibilities of the local cooling unit, control methods and measurement of the temperature fields.
\end{abstract}

Keywords - Material forming; local cooling; temperature field; cooling device; thermo-camera; pyro sensor; sheet metal blank.

\section{INTRODUCTION}

The automotive industry is continually increasing its demands on safe and lightweight body-in-white structures. One route available to achieving higher passive safety and reduced weight in vehicles involves using hot-stamped (press-hardened) parts. The numbers of these parts in the automotive sector have seen an exponential increase in recent years. [1] As the process is continuously being developed and enhanced, designers are continuing to come up with ever more complex and intricate parts, which are difficult to produce using exisiting technologies. [2] Additional requirements are also emerging for reducing the sheet thickness in these parts to around 1 millimetre. [3] This leads to severe problems in both handling and forming operations. Thin sheets fail more easily because they reach their formability limit sooner than materials with a 'normal' thickness. One of the mechanisms involved is local thinning, which limits the attainable drawing depth and the achievable complexity of the shape of the product. Various techniques are being explored to mitigate this problem and to enable intricate products to be made. A deliberate alteration of the flow stress levels in the blank is one available option. Since flow stress also depends on temperature, the plasticity properties in potential failure locations can be varied by controlling the temperature field in the blank. [4] In practice, controlled in-process cooling of the critical locations needs to be provided to reduce susceptibility to thinning and failure. FE analysis of the process can identify these potential failure locations. Controlled cooling of these locations should provide not only the desired local temperatures but also optimal temperature gradients in the transition regions.
An experimental facility has been built for testing active cooling devices, as well as control electronics, sensors, and control and monitoring software.

Various experimental set-ups and configurations can be tested at this facility, including workpiece handling, different cooling media and other aspects of the process.

\section{HARDWARE DESCRIPTION}

The hardware of the control system is based on a high performance 32-bit Cortex-M4 microcontroller STM32F411RE by STMicroelectronics. It features a rich set of peripherals for real-time control and support for generating and precise timing of logical control signals. Automotive gasoline and LPG injectors are used for water and air cooling. Both kinds of injectors need different controlling methods. A block diagram of the driving circuit is shown in Fig. 1.

\section{A. Gasoline injectors}

An automotive gasoline injector was used for local cooling by water or air without an additional nozzle. The nominal voltage of this injector is $12 \mathrm{~V}$ and the winding resistance is $14 \Omega$. The driving circuit consists of a MOSFET transistor that turns on/off the injector current.

\section{B. LPG injectors}

An automotive LPG injector was used for local cooling by air with a specially developed nozzle. The nominal voltage of this injector is $12 \mathrm{~V}$ and the winding resistance is $2 \Omega$. About $4 \mathrm{~A}$ is required to turn on the current. When the injector is turned on the hold current is only around $2 \mathrm{~A}$. For this reason the switching MOSFET transistor is controlled by PWM

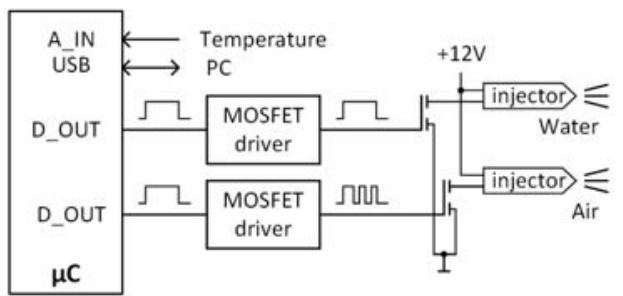

Figure 1. Block diagram of the driving circuit 
modulation. The injector switch on the transistor is turned on with a $100 \%$ duty cycle. After the injector current increases above the turn on value the PWM duty cycle is decreased. This reduces the injector current to the hold value. The PWM modulation is generated by the injector driver independently of the control microcontroller. In more detail in [5].

\section{SOFTWARE DESCRIPTION}

The software implemented in the control system evaluates the analogue input signal coming from the temperature sensor - a thermo-camera or pyro sensor which scans the blank temperature field. The output signals for the local cooling injector drivers are then generated depending on the temperature. After the heated blank is inserted, the algorithm evaluates its presence from the exceeded upper threshold temperature. Then, at a naturally decreasing temperature, it waits for the fall threshold temperature (see Fig. 2). Then the pulse bursts are initiated for all drivers.

Three injectors were used during the experimental testing and measurement, but any number of driving outputs can be used as the common hardware is independent of the control algorithm. The state machine implemented in the program allows expansion to the maximum number of free input and output pins of the microcontroller. The pulse burst is individually generated for each injector driver after the START trigger event. All the timing parameters and burst repeat numbers of any driver signal are fully configurable and independent of any other drivers see Fig. 3.

Despite the full independence of pulse generation for each channel, an alternate synchronous mode is possible. That is, the mode in which the timing and repetition parameters are common to all injector drivers.

The user application interface is implemented using a terminal connection with a personal computer. It enables the user mode configuration and settings of all algorithm parameters for each driver. These are: the time delay of pulse burst Tdi, the active level THi and the passive level TLi durations of one single pulse and repeat count $\mathrm{Ni}$ for each i-channel - see Fig. 3. The time resolution of all parameters is 1 millisecond in the range of 0 to 9999999 milliseconds. This range is independent of the injector type. An automatic mode or a manual trigger mode using the computer keyboard are selectable. Optionally, hardware push button triggering is also possible.

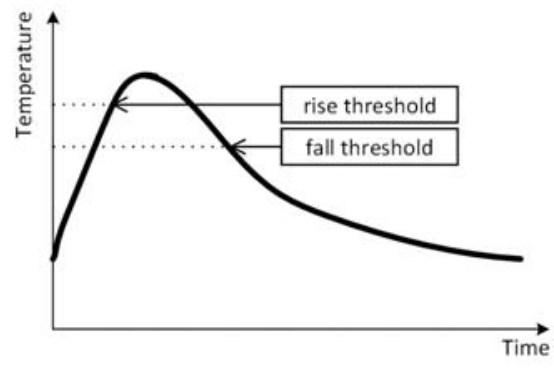

Figure 2. Thresholds and the start pulse generation

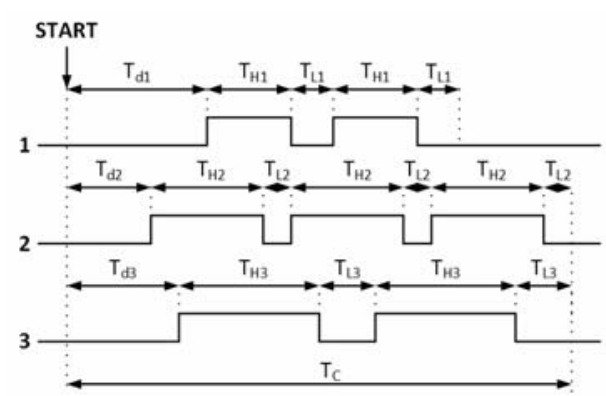

Figure 3. Waveform of driving signals

The analogue input trigger signal coming from the temperature sensor is normalized in the voltage range 0 to $10 \mathrm{~V}$. This range is mapped into 4096 digital levels. The rise threshold temperature point and the fall threshold temperature point mentioned above can be modified in this range as well as using the terminal user interface.

All tests and experimental measurements on various blanks of sheet metal were performed using the control algorithm mentioned above. The results obtained from these experiments will be exploited for parameterization of the final control algorithms used in the cooling facility.

\section{EXPERIMENTS AND RESULTS}

Several experiments were performed during the project. The goals of these tests were to check the cooling unit and to compare the possibilities of cooling by air and by water. Standard gasoline and LPG injectors were used at the beginning, but for local cooling it is necessary to use specially designed nozzles.

\section{A. Measuring station arrangement}

The measuring stand is composed of the electronic cooling unit with different types of injectors, nozzles, an optional mask, a TIM M1 thermo-camera with A/D input/output interface and a PC for data processing and setting the cooling unit parameters via a USB interface. A block diagram of the stand layout is shown in Fig. 4.

The project was designed to use different cooling media (air and water), so the arrangement with cooling from one side of the blank and measuring from the other side was used. This solution eliminates the

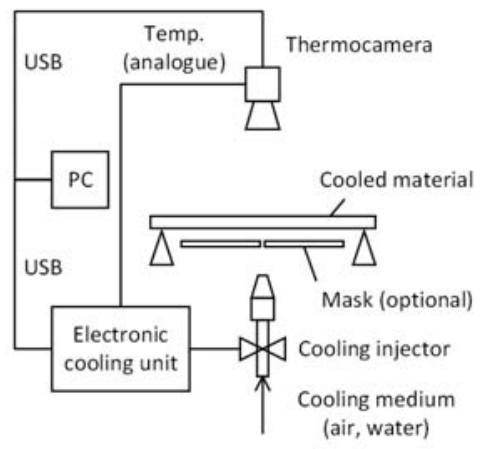

Figure 4. Measuring stand 
possible influence of steam on non-contact temperature measurement by the thermo-camera during water cooling.

A short wave infrared camera TIM M1 (MicroEpsilon) was chosen for temperature measurement. This camera works in a spectral range $0.92 \mu \mathrm{m}$ $1.1 \mu \mathrm{m}$. It is good for measuring metal surfaces because a short wave device reduces the measurement errors if emissivity is incorrectly adjusted [6].

All measurements were made on $22 \mathrm{MnB}$ steel blanks $200 \times 300 \mathrm{~mm}$ with thicknesses of $1 \mathrm{~mm}$ or $1.5 \mathrm{~mm}$. The results presented in the following paragraphs are for $1 \mathrm{~mm}$ metal sheets.

\section{B. Cooling by water}

The first experiments were carried out for cooling by water. The main goal was to verify the possibility of controlling the speed of cooling by different duty cycles and to confirm the expected advantages of intermittent water cooling over continuous water cooling. The following results were measured using the VDO A2C59511911 gasoline injector.

Figure 5 shows the dependency of the cooling efficiency on the duty cycle. This experiment assumes a constant time of water injection $(450 \mathrm{~ms})$. The line (a) presents the results for continuous cooling and the lines (b-h) illustrate intermittent cooling with period $20 \mathrm{~ms}$, the number of repetitions (NoR) 30 and different duty cycles. The measurement and results are summarized in Tab. I.

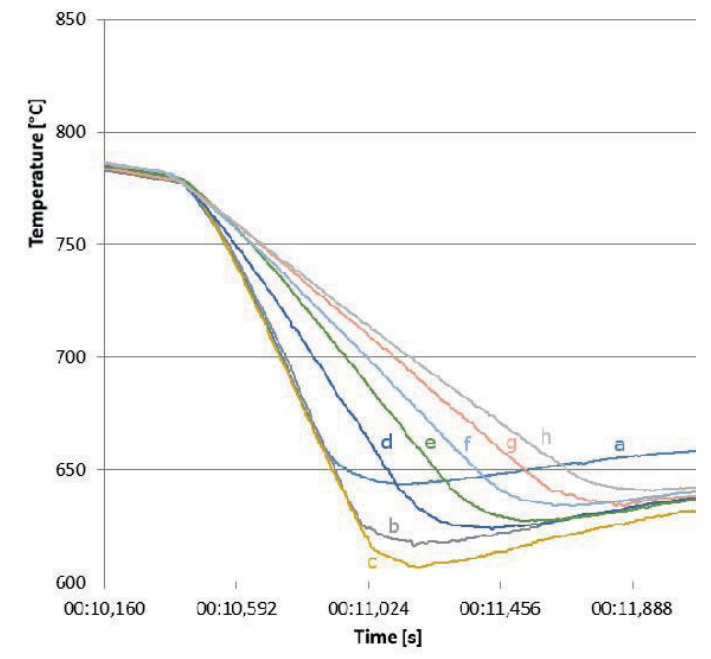

Figure 5. Cooling by water with different duty cycle

TABLE I. THE SPEED OF COOLING BY WATER

\begin{tabular}{|c|c|c|c|c|c|}
\hline \multicolumn{3}{|c|}{ Cooling parameters } & \multirow{2}{*}{$\begin{array}{c}\text { Temp. } \\
\text { difference } \\
{\left[{ }^{\circ} \mathrm{C}\right]}\end{array}$} & \multirow{2}{*}{$\begin{array}{c}\text { Speed of } \\
\text { cooling } \\
{\left[{ }^{\circ} \mathrm{C} / \mathrm{s}\right]}\end{array}$} & \multirow{2}{*}{$\begin{array}{l}\text { Line in } \\
\text { figure }\end{array}$} \\
\hline $\begin{array}{c}\text { Ton } \\
\text { [ms] }\end{array}$ & $\begin{array}{l}\text { Toff } \\
{[\mathrm{ms}]}\end{array}$ & $\begin{array}{c}\text { NoR } \\
{[-]}\end{array}$ & & & \\
\hline 450 & 1 & 1 & -112.8 & -250.1 & $\mathrm{a}$ \\
\hline 15 & 3 & 30 & -143.2 & -265.2 & $\mathrm{~b}$ \\
\hline 15 & 5 & 30 & -159.9 & -266.5 & $\mathrm{c}$ \\
\hline 15 & 10 & 30 & -140.9 & -187.9 & $\mathrm{~d}$ \\
\hline 15 & 15 & 30 & -139.9 & 155.4 & $\mathrm{e}$ \\
\hline 15 & 20 & 30 & -137.7 & -131.1 & $\mathrm{f}$ \\
\hline 15 & 25 & 30 & -135.4 & -112.8 & $\mathrm{~g}$ \\
\hline 15 & 30 & 30 & -134.3 & -99.5 & $\mathrm{~h}$ \\
\hline
\end{tabular}

\section{Cooling by air}

The second set of experiments was done for cooling by air. The main goal was to compare the efficiency of air and water.

Figure 6 shows the temperature curves for continuous cooling by air with process times from 0.5 $\mathrm{s}$ to $3 \mathrm{~s}$-lines (b) to (g) in comparison with natural cooling (a). The results in Fig. 6 and Tab. II present higher cooling efficiency for higher temperatures of material. This causes a slight deviation in results derived from curves (b) and (g) where the starting temperature of cooling was slightly lower than other measurements.

The results in Tab. I and Tab. II confirm the assumptions of the higher efficiency of cooling by water than by air and provide an idea about the possible speed of cooling. But it is necessary to point out that the speed is dependent on many other factors (the pressure of the cooling medium, its temperature, the distance between the material and the nozzles of the injectors, etc.).

\section{Selective cooling according to given relief}

One of the main goals of the project is the selective cooling of a sheet metal blank to obtain a better material structure after hot forming. The experiments presented in the previous paragraphs used a common gasoline injector for cooling. It is possible to use this cooling for a relatively circular area of the material. The size of this area is dependent on the construction of injectors and their distance from the cooled material.

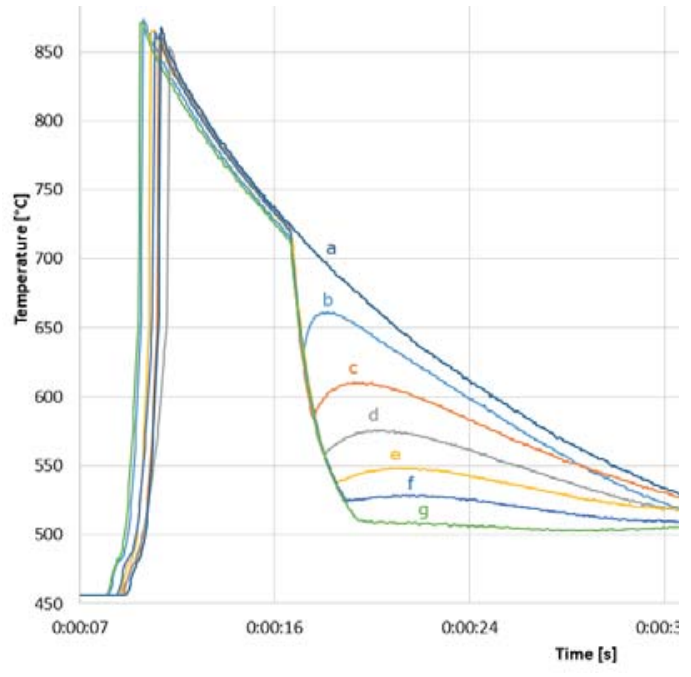

Figure 6. Cooling by air with different process time

TABLE II. CONTINUOUS COOLING BY AIR

\begin{tabular}{|c|c|c|c|}
\hline Ton [ms] & $\begin{array}{c}\text { Temp. difference } \\
{\left[{ }^{\circ} \mathbf{C}\right]}\end{array}$ & $\begin{array}{c}\text { Speed of } \\
\text { cooling } \\
{\left[{ }^{\circ} \mathbf{C} / \mathbf{s}\right]}\end{array}$ & $\begin{array}{c}\text { Line in } \\
\text { figure }\end{array}$ \\
\hline \multicolumn{3}{|c|}{ Natural cooling } \\
\hline 500 & -58.7 & -122 & $\mathrm{a}$ \\
\hline 1000 & -121.7 & -121.7 & $\mathrm{~b}$ \\
\hline 1500 & -147.4 & -99.5 & $\mathrm{~d}$ \\
\hline 2000 & -166.7 & -83.4 & $\mathrm{e}$ \\
\hline 2500 & -181.3 & -73.1 & $\mathrm{f}$ \\
\hline 3000 & -187.9 & -62.6 & $\mathrm{~g}$ \\
\hline
\end{tabular}


The next experiments were dedicated to selective cooling of a linear area of a blank. A group of three injectors distributed linearly with a minimum distance was tested in the first measurements. Unfortunately, the results were not sufficient because the size of the injectors did not allow thin and relatively homogenously cooled areas.

The group of injectors with masking was tested to obtain a narrower area. The temperature distribution during an experiment with one water injector, two air injectors and a mask with a linear slot (width $=1 \mathrm{~mm}$ ) is shown in Fig. 7 The temperature maps in time 800 $\mathrm{ms}$ (end of cooling by water - Ton $=15 \mathrm{~ms}$, Toff $=5 \mathrm{~ms}$, $\mathrm{NoR}=40$ ) and $3000 \mathrm{~ms}$ (end of cooling by air Ton $=3000 \mathrm{~ms}$, Toff $=1 \mathrm{~ms}$, NoR $=1$ ) are presented. The positive effect of masking is noticeable for cooling by air but there is almost no effect for cooling by water. These results are for a distance of $10 \mathrm{~mm}$ between the material and the mask and $25 \mathrm{~mm}$ between the mask and the injector.

Insufficient homogeneity of the temperature distribution for cooling continuous relief was observed. Therefore we developed and tested a special nozzle which was constructed from a pipe $(6 \mathrm{~mm}$ diameter) with $1 \mathrm{~mm}$ holes linearly distributed on one side of the pipe. The resulting temperature distribution is much better than for the previous solution based on a group of injectors with masking. This is shown in Fig. 8. In this case an LPG injector (LPG Barracuda $\mathrm{SE} 130 \mathrm{Nl}$ ) was used for higher airflow through the nozzle. The temperature map in the figure is for $3000 \mathrm{~ms}$ (end of cooling - Ton $=3000 \mathrm{~ms}$, Toff $=1 \mathrm{~ms}, \mathrm{NoR}=1)$.

$20 \quad 40 \quad 60 \quad 80 \quad 100120140160180200220240$

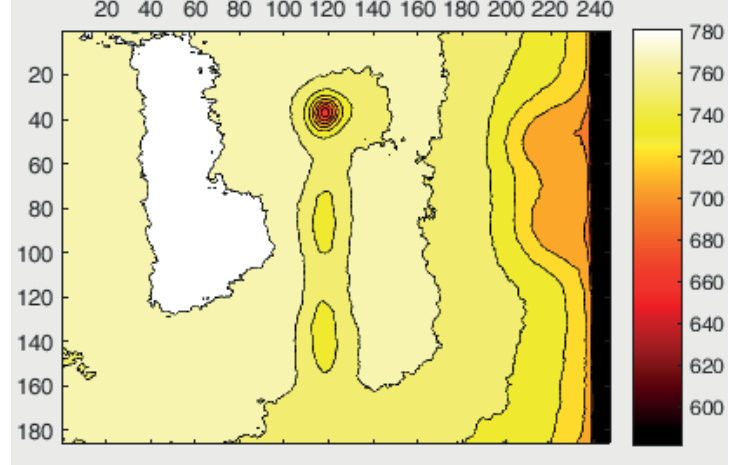

(a) time $800 \mathrm{~ms}$

$20 \quad 40 \quad 60 \quad 80 \quad 100120140160180200220240$

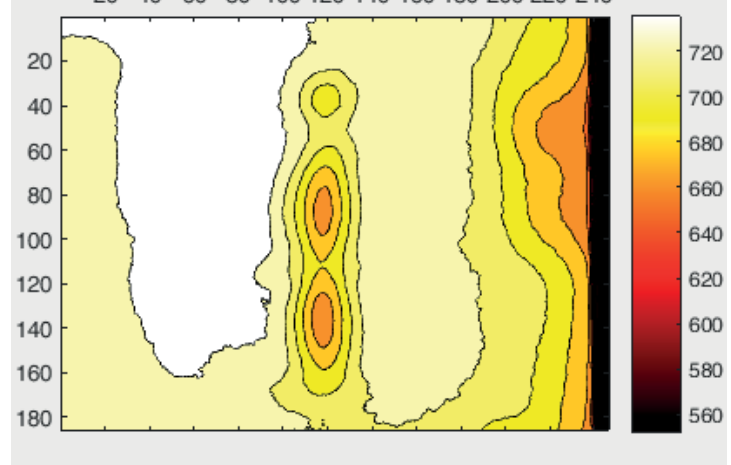

(b) time $3000 \mathrm{~ms}$

Figure 7. Temperature distribution -3 injectors with a mask
$20 \quad 40 \quad 60 \quad 80 \quad 100120140160180200220240$

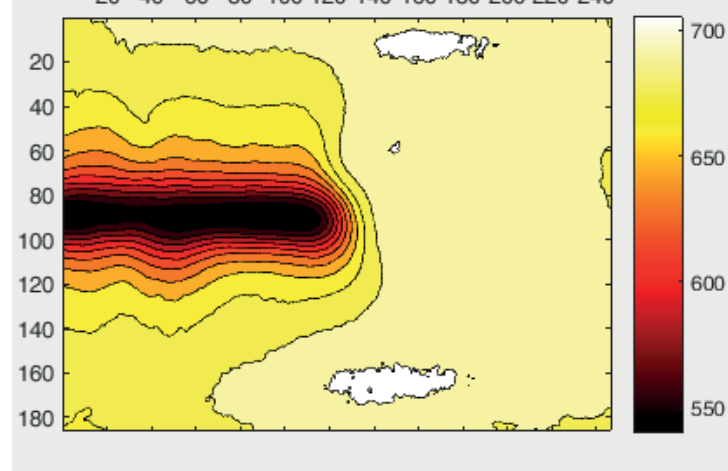

Figure 8. Temperature distribution-developed linear nozzle

\section{CONCLUSIONS AND FUTURE WORK}

An experimental rig was successfully built for testing active cooling devices. The rig is one part of a fully automatic stand for hot forming steel sheets. The designed cooling unit is capable of changing the temperature on the sheet locally and dynamically. This makes it possible to change the microstructure and modify the local technological properties of the blank. A final technologically tailored blank improves the formability and reduces the risk of fracture in critical areas of intensive stretches.

In the future many measurements will be required for determining the dependency of cooling intensity and its influence on technological properties. The subsequent development will be focused on cooling the blank to achieve more complex shape relief with user required properties for crash relevant parts of car bodies

\section{ACKNOWLEDGMENTS}

This paper includes results created within the projects CZ.01.1.02/0.0/0.0/15 019/0004620 and SGS-2018001 . The projects are subsidised by the Ministry of Industry and Trade, and by the Ministry of Education, Youth and Sports from the European Regional Development Fund and resources of the state budget of the Czech Republic.

\section{REFERENCES}

[1] R. Neugebauer, F. Schieck, S. Polster, A. Mosela, A. Rautenstrauch, J. Schönherr, N. Pierschela, "Press hardening An innovative and challenging technology", Archives of Civil and Mechanical Engineering. 2012. Vol. 12, no. 2, p. 113-118

[2] M. Merklein, M Johannes, M. Lechner, A. Kuppert, "A review on tailored blanks - Production, applications and evaluation", Journal of Materials Processing Technology. 2014. Vol. 214, no. 2, p 151-164.

[3] G. Georgiadis, A. E. Tekkaya, P. Weigerta, J. Weihera. H Kurza, "Investigations on the Manufacturability of Thin Press Hardened Steel Components" Procedia CIRP. 2014. Vol. 18 p. $74-79$

[4] H. Jirková, B. Mašek, "Process for producing hot drawn plate steel parts”, Czech Republic, Patent Number 305697, 2016.

[5] K. G. Buss and A. Marshall, "PWM controllers for automotive applications," In: Automotive Power Electronics, USA, 1989, p. 114-118. DOI: 10.1109/APE.1989.97166.

[6] Optris $\mathrm{GmbH}$, "Basic Principle of non-contact temperature measurement" [online] [viewed 2019-01-29]. Available from: https://bit.ly/2ZBJNo5 